\title{
Preparation of Inclusion Complexes of Amlodipine Base and its Besylate and Maleate Salts with Hydroxy Propyl $\beta$-cyclodextrin -A study on Stereospecific Dissolution
}

\author{
Jaganmohan Somagoni ${ }^{1,2}$, Sunil Reddy ${ }^{1}$, Vinay Kumar Katakam ${ }^{1}$, Someshwar Koorelli ${ }^{1}$, Sarangapani Manda ${ }^{2}$ and Madhusudan Y Rao ${ }^{1 *}$
}

${ }^{1}$ Centre for Biopharmaceutics and Pharmacokinetics, University College of Pharmaceutical Sciences, Kakatiya University, Warangal - 506009 (A.P) India

${ }^{2}$ Department of Medicinal Chemistry, University College of Pharmaceutical Sciences, Kakatiya University, Warangal - 506009 (A.P) India

\begin{abstract}
The objective of this work was preparation of inclusion complexes of amlodipine base and its besylate and maleate salts with hydroxy propyl $\beta$-cyclodextrin to improve the dissolution and to investigate the stereospecific dissolution of amlodipine enantiomers.

Different techniques like physicl mixing, kneading and solvent evaporation were tried to prepare the inclusion complexes of amlodipine base and its besylate and maleate salts with hydroxy propyl $\beta$-cyclodextrin (HPBC). Dissolution of prepared inclusion complexes was performed using USP type II apparatus in $0.1 \mathrm{~N} \mathrm{HCl}$ at $75 \mathrm{rpm}$ with temperature being maintained at $37 \pm 0.5^{\circ} \mathrm{C}$. Chromatographic separation of amlodipine enantiomers was performed on a Shimadzu HPLC System (Japan) equipped with UV-Visible detector using Chiral AGP column (100 x $4.6 \mathrm{~mm}$ I.D., $5 \mu$ particle size).

Improvement in the dissolution was found with racemic amlodipine base where as no improvement was found with amlodipine besylate and maleate salts $(p>0.05)$. This indicates the formation of inclusion complexes with only racemic amlodipine base $(p<0.05)$ which was also supported by their FTIR and DSC spectra.

In case of physical mixing no inclusion complexes were formed even with enantiomers of amlodipine base $(p>0.05)$. Stereospecific dissolution was observed with pure enantiomers of amlodipine base when its inclusion complexes were prepared by solvent evaporation method with l:1 \& 1:2 molar ratios but not with 1:3 molar ratio.
\end{abstract}

Keywords: Stereospecificity; Inclusion complex; Hydroxy Propyl $ß$ -Cyclodextrin; Amlodipine enantiomers; Chiral HPLC

\section{Introduction}

Cyclodextrins are a family of cyclic oligosaccharides with a hydrophilic outer surface and a lipophilic central cavity. Cyclodextrin molecules are relatively large with a number of hydrogen donors and acceptors and, thus, in general they do not permeate lipophilic membranes. Cyclodextrins are widely used as "molecular cages" in the pharmaceutical, agrochemical, food and cosmetic industries. In the pharmaceutical industry they are used as complexing agents to increase the aqueous solubility of poorly soluble drugs and to increase their bioavailability and stability $[1,2]$.

In aqueous solutions, cyclodextrins are able to form inclusion complexes with many drugs by taking up the drug molecule or some lipophilic moiety of the molecule, into the central cavity. No covalent bonds are formed or broken during complex formation, and the drug molecules in complex are in rapid equilibrium with free molecules in the solution. The driving forces for the complex formation include release of enthalpy-rich water molecules from the cavity, hydrogen bonding, Vander Waals interaction, charge transfer interaction etc $[3,4]$.

Amlodipine is a long-acting dihydropyridine calcium channel blocker. It is effective in the treatment of angina pectoris and hypertension $[5,6]$. The S-enantiomer has been reported to be more active than the R-enantiomer without the concomitant liability of adverse effects associated with the racemic mixture of amlodipine $[7,8]$. Amlodipine is poorly soluble in water whose bioavailability is dissolution dependent. Many studies have suggested enantioselective differences in the dissolution of chiral drugs, but the significance of these differences in terms of therapeutic outcomes has been controversial [9-11].

Drug chirality is now a major theme in the design, discovery, development, launching and marketing of new drugs. The advances in stereoselective bioanalysis led to a new awareness of the importance of stereoselective pharmacodynamics and pharmacokinetics, enabling the differentiation of the relative contributions of enantiomers to overall drug action [12-14].

Maggi et al. reported some stereoselective dissolution of some racemic drugs from core hydrophilic matrices that were press-coated with chiral excipients including pectin, galactomanan, and steroglucan [15].

Hence the major objective to carry out this work was preparation of inclusion complexes of amlodipine base and its besylate and maleate salts with hydroxy propyl $\beta$-cyclodextrin to improve the dissolution and to investigate the stereo specific dissolution of amlodipine enantiomers.

*Corresponding author: Prof. Y. Madhusudan Rao, Centre for Biopharmaceutics and Pharmacokinetics, University College of Pharmaceutical Sciences, Kakatiya University, Warangal - 506009 (A.P), India, Tel: +91-870-2438844; Fax: +91-8702570543; E-mail: yamsani123@gmail.com

Received March 08, 2011; Accepted May 17, 2011; Published May 21, 2011

Citation: Somagoni J, Reddy S, Katakam VK, Koorelli S, Manda S, et al. (2011) Preparation of Inclusion Complexes of Amlodipine Base and its Besylate and Maleate Salts with Hydroxy Propyl B -cyclodextrin -A study on Stereospecific Dissolution. Pharm Anal Acta 2:123. doi:10.4172/2153-2435.1000123

Copyright: @ 2011 Somagoni J, et al. This is an open-access article distributed under the terms of the Creative Commons Attribution License, which permits unrestricted use, distribution, and reproduction in any medium, provided the original author and source are credited. 
Citation: Somagoni J, Reddy S, Katakam VK, Koorelli S, Manda S, et al. (2011) Preparation of Inclusion Complexes of Amlodipine Base and its Besylate and Maleate Salts with Hydroxy Propyl B -cyclodextrin -A study on Stereospecific Dissolution. Pharm Anal Acta 2:123. doi:10.4172/2153-2435.1000123

Page 2 of 8

\section{Materials and Methods}

\section{Materials}

Amlodipine base and its besylate and maleate salts were a kind gift from smruthi organics Pvt.Ltd. Sholapur, Maharastra, India.

Hydroxy Propyl $\beta$-Cyclodextrin (HPBC) is a kind gift from Nectar Pharma Pvt. Ltd., India. All other chemicals used were of analytical grade.

\section{Preparation of inclusion complexes}

The inclusion complexes of racemic amlodipine base and its besylate \& maleate salts with HPBC were prepared by physical mixing (PM) and kneading methods $(\mathrm{KN})$ in 1:1 molar ratio where as in 1:1 (SE1), 1:2 (SE2) and 1:3(SE3) molar ratios by solvent evaporation method.

Physical mixing: Amlodipine base was mixed thoroughly with HPBC in 1:1 molar ratio in the dry state. The mixtures were then passed through \# 100 mesh. In a similar way physical mixtures of the amlodipine besylate and maleate salts were prepared and labelled as follows.

\section{RS -AB: PM for Racemic-Amlodipine base}

RS -ABS: PM for Racemic-Amlodipine besylate salt

RS -AMS: PM for Racemic-Amlodipine maleate salt

Kneading method: Accurately weighed quantity of HPBC was placed into a mortor moistened with water and kneaded to the paste consistency. Then weighed quantity of amlodipine base was introduced slowly and kneaded for $30 \mathrm{~min}$. During this process appropriate quantity of water was added to maintain suitable consistency. Finally obtained paste was kept in an oven at $40^{\circ} \mathrm{C}$ until it was dried completely. In a similar way kneading mixtures of the amlodipine besylate and maleate salts were prepared and labelled as follows.

RS-AB: KN for Racemic-Amlodipine base

RS-ABS: KN for Racemic-Amlodipine besylate salt

RS-AMS: KN for Racemic-Amlodipine maleate salt

Solvent evaporation method: Accurately weighed quantities of amlodipine base was dissolved in ethanol separately, to which required moles of HPBC in hot distilled water was added drop wise with continuous stirring for $30 \mathrm{~min}$. Then the solution was dried under vacuum until it was dried completely. Similar procedure was applied to prepare the inclusion complexes of amlodipine besylate and maleate salts and the prepared inclusion complexes were labelled as follows.

RS-AB: SE for Racemic-Amlodipine base

RS -ABS: SE for Racemic-Amlodipine besylate salt

RS -ABS: SE for Racemic-Amlodipine maleate salt

\section{Identification of inclusion complexes} DSC.

The obtained inclusion complexes were characterized by FTIR and

Fourier transform infra red spectroscopy (FTIR): FTIR spectra were obtained on FTIR-2000 model (PERKIN-ELMER). Samples were prepared in $\mathrm{KBr}$ disks ( $2 \mathrm{mg}$ sample in $200 \mathrm{mg} \mathrm{KBr}$ ). Data was collected over a spectral region from 4000 to $400 \mathrm{~cm}-1$.

Differential Scanning Calorimetry (DSC): DSC analysis was performed for amlodipine base and its besylate and maleate salts and their inclusion complexes. Thermograms were recorded on a METTLER TOLEDO DSC. (Model: DSC 827). Samples of 5-7mg weight were heated in hermetically sealed aluminum pans over temperature range of $10^{\circ} \mathrm{C}-300^{\circ} \mathrm{C}$ at a constant rate of $10^{\circ} \mathrm{C} / \mathrm{min}$ under nitrogen purge $(30 \mathrm{ml} / \mathrm{min})$.

\section{Dissolution study}

Dissolution of an accurately weighed quantity of amlodipine HPBC inclusion complex equivalent to $10 \mathrm{mg}$ of amlodipine was done using USP type II apparatus (LABINDIA Model: DS 8000) in $0.1 \mathrm{~N} \mathrm{HCl}$ at $75 \mathrm{rpm}$ with temperature being maintained at $37 \pm 0.5^{\circ} \mathrm{C}$. Samples were withdrawn at 5,15,30,45 and $60 \mathrm{~min}$ time points and were analyzed for dissolved amlodipine using chiral AGP column at $235 \mathrm{~nm}$. The dissolution experiments were done in triplicate. The dissolution (cumulative \% drug release vs time in hrs) profiles of pure amlodipine base and their inclusion complexes obtained by various methods with HPBC were shown in Figure 6.

\section{Chromatographic apparatus and conditions}

Chromatographic separation of amlodipine enantiomers was performed on a Shimadzu HPLC System (Japan) equipped with UV-Visible detector using Chiral AGP column (100 x $4.6 \mathrm{~mm}$ I.D. $5 \mu$ particle size). The wavelength for UV detection was set at 235 $\mathrm{nm}$. The mobile phase was $10 \mathrm{mM}$ Ammonium acetate buffer with $1 \%$ 1-Propanol adjusted to $\mathrm{pH} 4.6$ at a flow rate of $0.9 \mathrm{ml} \mathrm{min}^{-1}$ with an injector valve fitted to a $50 \mu \mathrm{l}$ volume sample loop. The retention times for $\mathrm{R}$ and $\mathrm{S}$ enantiomers of amlodipine were 5 and 7 minutes respectively (Figure 1).

\section{Statistical analysis}

All the results were tested for statistical significance using t-test. The dissolution values of inclusion complexes of racemic amlodipine base prepared by different methods were compared with the dissolution values of pure racemic amlodipine base and with each other. This was also done with amlodipine besylate and maleate using Jandel Scentifica software. The difference in the sample means were considered significant at $\mathrm{p}<0.05$

\section{Results and Discussion}

\section{DSC and FTIR Studies}

Inclusion complexes of racemic amlodipine base and its besylate Chiral separation of amlodipine enantiomers

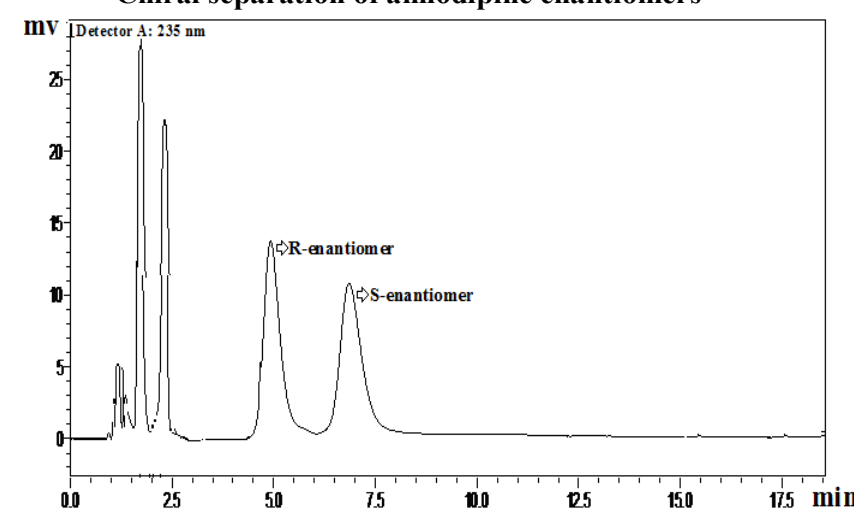

Figure 1: Chromatogram showing the chiral separation of amlodipine enantiomers. 
Citation: Somagoni J, Reddy S, Katakam VK, Koorelli S, Manda S, et al. (2011) Preparation of Inclusion Complexes of Amlodipine Base and its Besylate and Maleate Salts with Hydroxy Propyl B -cyclodextrin -A study on Stereospecific Dissolution. Pharm Anal Acta 2:123. doi:10.4172/2153-2435.1000123

Page 3 of 8

and maleate salts with HPBC can be obtained by different methods. In this study, physical mixing, kneading and solvent evaporation methods were used.

According to literature data, the inclusion complexes of the drugs with cyclodextrin are formed in a non-covalent manner, without chemical bonds. Their formation involves mainly hydrophobic interactions and van der Waals bonds, less frequently hydrogen bonds. For this reason the identification of the clathrates is a complex problem. In this study it has been confirmed on the basis of DSC and FTIR studies.

From the dissolution studies, it was confirmed that no improvement in the dissolution was found with the inclusion complexes prepared with amlodipine base and its besylate and maleate salts by mere physical mixing.

In no method, improvement in the dissolution was found with the inclusion complexes made with amlodipine besylate and maleate salts. The probable reason for this could be the inability of HPBC to accommodate the besylate and maleate salts as their size is quite larger than cavity of HPBC.

The complexation process of Amlodipine base with the HPBC has been confirmed by the FTIR spectroscopy. The FTIR spectra in case of amlodipine base were significantly different from its corresponding FTIR spectra of the pure drugs where as no significant difference was found in case of amlodipine besylate and maleate salts (Figure 2). In the FTIR spectra of the inclusion compounds of the amlodipine base, the bands in the range $3250-3450 \mathrm{~cm}^{-1}$ assigned to the stretching vibrations of the $\mathrm{N}-\mathrm{H}$ bonds in the amlodipine dihydropyridine ring. The differences also appear in the band corresponding to the vibrations of carbonyl groups in the ester bonds. In the spectra of the pure drugs the band occurs at $1670-1690 \mathrm{~cm}^{-1}$, while in the spectra of the corresponding inclusion complexes it is broadened and shifted towards shorter waves. Some differences are also noted in the range 1000-1500 $\mathrm{cm}^{-1}$, assigned to the vibrations of multiple bonds in the unsaturated dihydropyridine ring of amlodipine. No differences were appeared in the band corresponding to the vibrations of carbonyl groups in the ester bonds of amlodipine besylate and maleate salts. Therefore the above results were conforming the formation of inclusion complexes with amlodipine base but not with besylate and maleate salts. This was also further conformed by DSC studies.

The DCS curves of amlodipine base and its besylate and maleate salts with and without complexation were shown in Figures 3, 4 and 5 respectively. The pure drugs show characteristic endothermic peaks corresponding to the melting point of the crystalline drugs i.e. at $173^{\circ} \mathrm{C}$ (Amlodipine base), $214^{\circ} \mathrm{C}$ (Amlodipine besylate) and $189^{\circ} \mathrm{C}$ (Amlodipine maleate). Thermograms of the inclusion complexes of amlodipine base did not show peaks in this region, implying inclusion of the drug into the HPBC cavity. The broad endothermic peaks at the beginning of the DSC curve have been related to the liberation of water from the HPBC groove. In case of RS-AB:KN \& RS-AB:SE the formation of inclusion complex was indicated by the shift of endothermic peak from $172^{\circ} \mathrm{C}$ to $194^{\circ} \mathrm{C} \mathrm{\&} 202^{\circ} \mathrm{C}$ respectively but no shift was observed with RS-AB:PM. Shift of endothermic peak was also not observed with amlodipine besylate and maleate salts implying the absence inclusion complex formation irrespective of the type of the method adopted to form the complex.

\section{Dissolution profiles and $s / \mathbf{r}$ ratios with a special investigation on stereospecificity}

One of the aims of the complexation with the cyclodextrin was to increase the drug dissolution; therefore, the dissolution profiles of all the obtained inclusion complexes and respective pure drugs were tested.

\section{FTIR spectra of amlodipine base and its besylate and maleate salts}

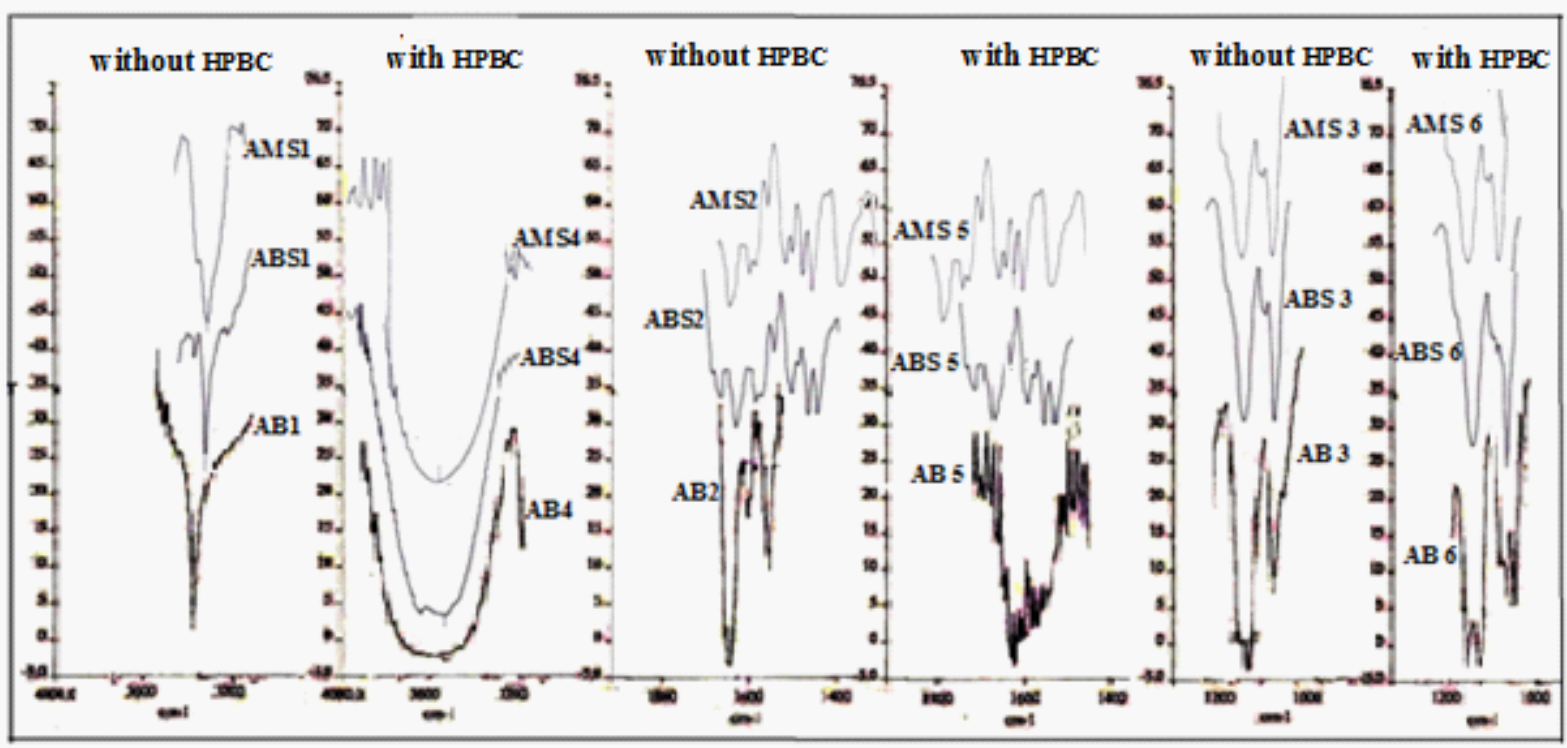

$A B$ : Amlodipine base, ABS: Amlodipine besylate, AMS: Amlodipine maleate HPBC: Hydroxyl Propyl $\beta$-Cyclodextrin

Figure 2: $A B 1, A B 2, A B 3, A B S 1, A B S 2, A B S 3, A M S 1, A M S 2$ and $A M S 3$ are the FTIR spectra obtained from the amlodipine base and its besylate and maleate salts whereas AB4, AB5, AB6, ABS4, ABS5, ABS6, AMS4, AMS5 and AMS6 are the FTIR spectra obtained from their inclusion complexes with HPBC (by solvent evaporation method at $1: 3$ molar ratio) respectively at their respective wavelengths. 
Citation: Somagoni J, Reddy S, Katakam VK, Koorelli S, Manda S, et al. (2011) Preparation of Inclusion Complexes of Amlodipine Base and its Besylate and Maleate Salts with Hydroxy Propyl B -cyclodextrin -A study on Stereospecific Dissolution. Pharm Anal Acta 2:123. doi:10.4172/2153-2435.1000123

\section{DSC THERMOGRAMS}

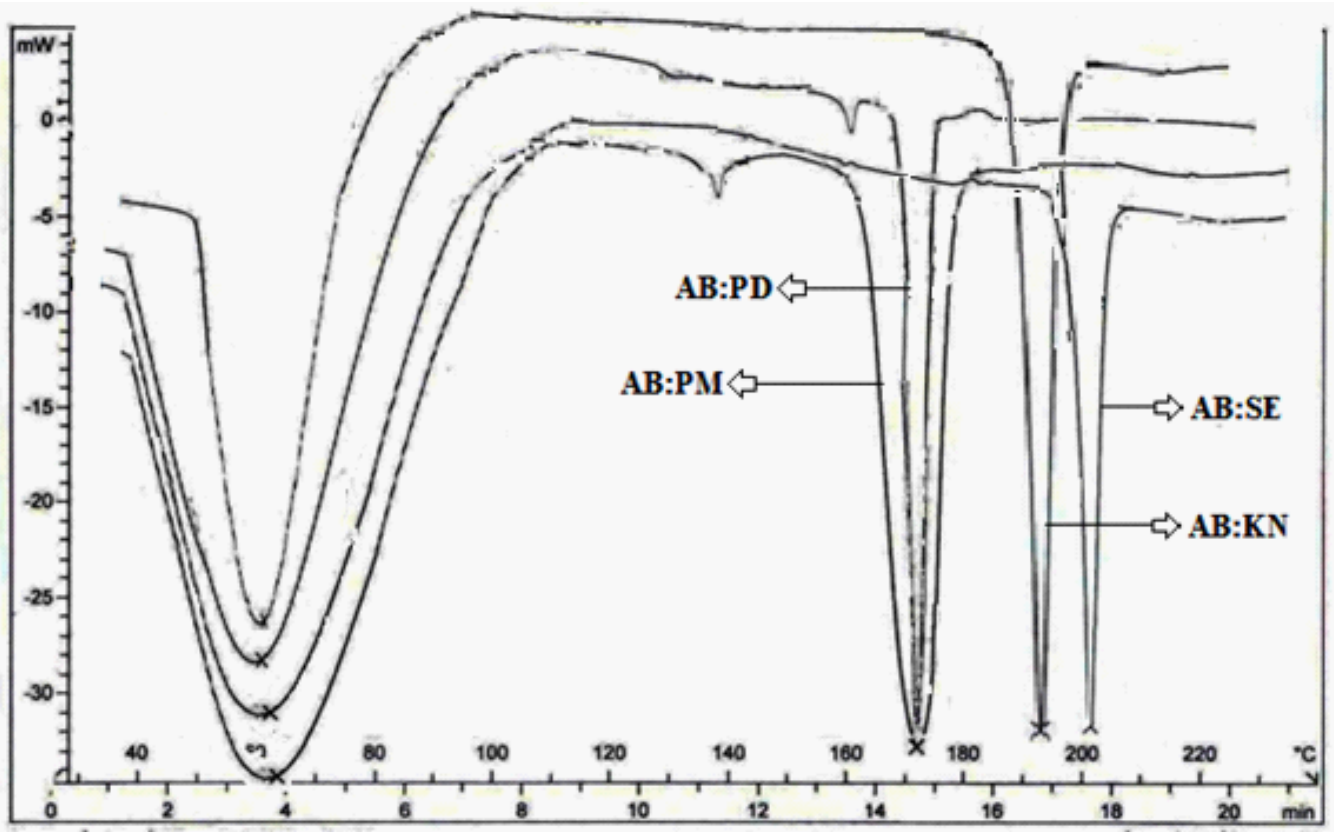

Figure 3: DSC curves obtained from pure amlodipine base (AB:PD) and from its inclusion complexes prepared with Hydroxyl Propyl $\beta$-Cyclodextrin (HPBC) by physical mixing (AB:PM), kneading ( $\mathrm{B}: \mathrm{KN})$ and solvent evaporation methods (AB:SE) respectively.

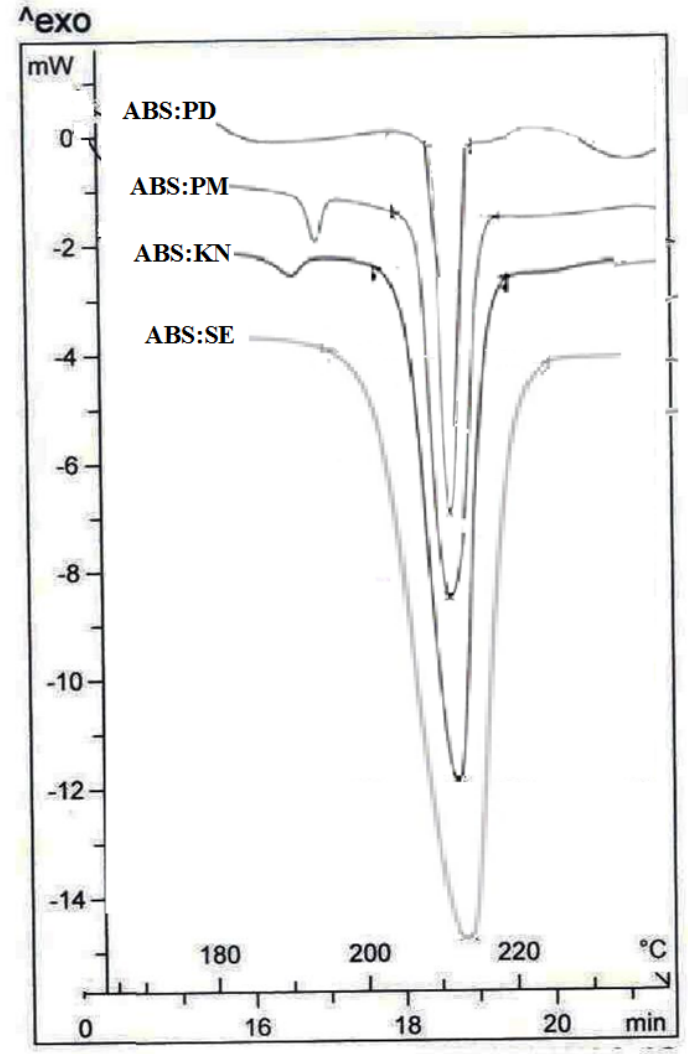

Figure 4: DSC curves obtained from pure amlodipine besylate (ABS:PD) and its inclusion complexes prepared with Hydroxyl Propyl $\beta$-Cyclodextrin (HPBC) by physical mixing (ABS:PM), kneading (ABS:KN) and solvent evaporation methods (ABS:SE) respectively.

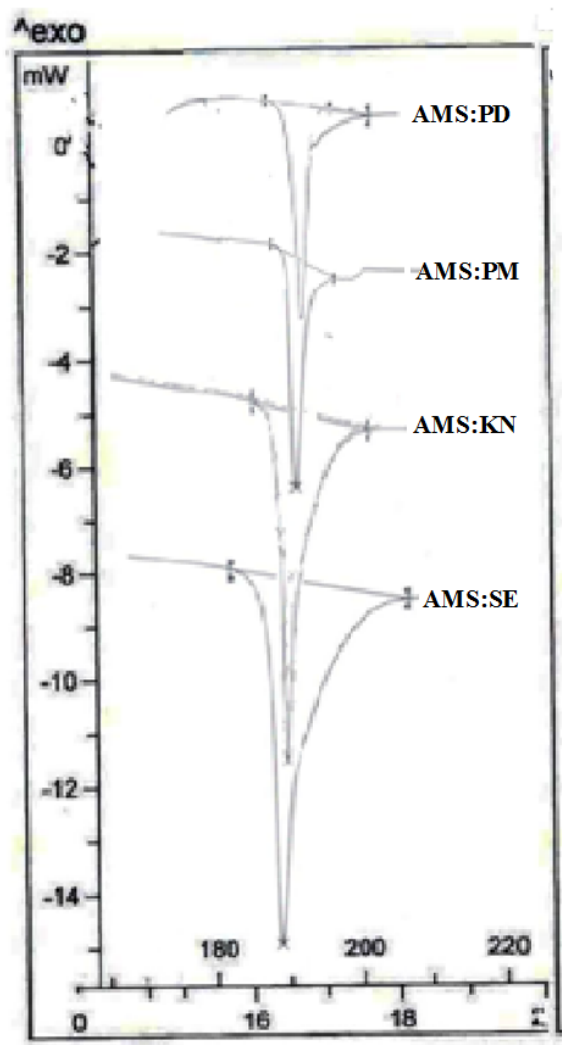

Figure 5: DSC curves obtained from pure amlodipine maleate (AMS:PD) and its inclusion complexes prepared with Hydroxyl Propyl $\beta$-Cyclodextrin (HPBC) by physical mixing (AMS:PM), kneading (AMS:KN) and solvent evaporation methods (AMS:SE) respectively. 
Citation: Somagoni J, Reddy S, Katakam VK, Koorelli S, Manda S, et al. (2011) Preparation of Inclusion Complexes of Amlodipine Base and its Besylate and Maleate Salts with Hydroxy Propyl B -cyclodextrin -A study on Stereospecific Dissolution. Pharm Anal Acta 2:123. doi:10.4172/2153-2435.1000123

Page 5 of 8

From the results mentioned in Tables 1 and 2, it was clear that there was no improvement in the dissolution with the inclusion complexes of amlodipine besylate and maleate salts with HPBC when compared with their pure forms $\{\mathrm{p}>0.05$; Tables $4(\mathrm{a})$ and $5(\mathrm{a})\}$. Therefore it was thought that there might be no complexation of besylate and maleate salts with HPBC. All the results given in the Tables 1 and 2 were also supported by the DSC thermograms shown in the Figures 4 and 5 . As there was no complexation with amlodipine besylate and maleate salts, there was no discrimination in the release profiles of individual amlodipine besylate and maleate enantiomers and their $S / R$ ratios. Hence the dissolution results and $S / R$ values of besylate and maleate salts were not depicted in the form of graphs.

No improvement in dissolution from RS-AB: PM, RS-ABS: PM and RS-AMS: PM was found when compared to the dissolution profiles of their pure forms. This indicates that no inclusion complexes were formed with physical mixing ( $\mathrm{p}>0.05)$.

No significant improvement in dissolution from RS-ABS: PM, RS-ABS: KN, RS-ABS: SE, RS-AMS: PM, RS-AMS: KN and RS-AMS:
SE was found when compared to the dissolution profiles of their pure forms ( $p>0.05)$.

This indicates that no inclusion complexes were formed with amlodipine besylate and maleate salts irrespective of the method adopted for inclusion complex formation. No significant stereospecificity was found when the dissolution profiles of $S \& R$ enantiomers of amlodipine besylate and maleate salts were compared with each other $\{p>0.05$ Table 4(b) and 5(b)\}, where as a significant stereospecificity was found in case of $S \& R$ amlodipine base enantiomers $\{\mathrm{p}<0.05$; Table $3(\mathrm{~b})\}$.

Improvement in the dissolution profiles of RS-AB: $\mathrm{KN}$ and RS-AB: SE was found when compared with the dissolution profiles of their respective pure base forms $(\mathrm{p}<0.05$; Table $3(\mathrm{a}))$.

This indicates the formation of inclusion complex with amlodipine base in both kneading and solvent evaporation techniques. The inclusion complexes prepared with 1:2 \& 1:3 molar ratios by solvent evaporation technique are shown much better improvement in dissolution when compared with the inclusion complexes prepared with 1:1 molar ratio and kneading method. This indicates the HPBC

\begin{tabular}{|c|c|c|c|c|c|c|}
\hline \multicolumn{7}{|c|}{$\%$ Drug release $(n=3)$} \\
\hline \multirow{2}{*}{$\begin{array}{l}\text { TIME } \\
\text { ( } \mathrm{min})\end{array}$} & \multicolumn{2}{|c|}{ PD (Mean $\pm S D)$} & \multicolumn{2}{|c|}{ PM (Mean $\pm S D)$} & \multicolumn{2}{|c|}{ KN (Mean士SD) } \\
\hline & $\mathbf{R}$ & $\mathbf{S}$ & $\mathbf{R}$ & $\mathbf{S}$ & $\mathbf{R}$ & $\mathbf{S}$ \\
\hline 5 & $86.93 \pm 3.24$ & $85.47 \pm 2.91$ & $87.37 \pm 2.18$ & $86.53 \pm 2.45$ & $86.23 \pm 2.45$ & $84.29 \pm 2.30$ \\
\hline 15 & $93.71 \pm 2.45$ & $94.40 \pm 3.28$ & $97.25 \pm 3.16$ & $96.75 \pm 1.84$ & $95.34 \pm 3.63$ & $95.26 \pm 3.06$ \\
\hline 30 & $98.56 \pm 3.47$ & $97.86 \pm 2.08$ & $99.29 \pm 3.14$ & $98.89 \pm 3.24$ & $98.57 \pm 2.36$ & $98.91 \pm 2.13$ \\
\hline 45 & $96.92 \pm 3.78$ & $96.81 \pm 3.03$ & $97.69 \pm 2.54$ & $96.45 \pm 2.72$ & $95.27 \pm 3.40$ & $95.38 \pm 3.14$ \\
\hline 60 & $95.18 \pm 2.96$ & $94.93 \pm 3.62$ & $95.26 \pm 2.37$ & $9279 \pm 3.81$ & $93.14 \pm 3.37$ & $92.12 \pm 3.35$ \\
\hline \multirow{2}{*}{$\begin{array}{l}\text { TIME } \\
\text { ( } \mathrm{min})\end{array}$} & \multicolumn{2}{|c|}{ SE1 (Mean士SD) } & \multicolumn{2}{|c|}{ SE2 (Mean士SD) } & \multicolumn{2}{|c|}{ SE3 (Mean士SD) } \\
\hline & $\mathbf{R}$ & $\mathbf{S}$ & $\mathbf{R}$ & $\mathbf{S}$ & $\mathbf{R}$ & $\mathbf{s}$ \\
\hline 5 & $85.02 \pm 3.02$ & $83.84 \pm 2.37$ & $87.25 \pm 2.98$ & $85.86 \pm 3.12$ & $86.47 \pm 2.84$ & $87.73 \pm 2.23$ \\
\hline 15 & $95.16 \pm 2.13$ & $94.95 \pm 3.30$ & $97.32 \pm 1.23$ & $98.89 \pm 2.93$ & $98.16 \pm 2.24$ & $98.53 \pm 1.97$ \\
\hline 30 & $98.78 \pm 2.56$ & $98.57 \pm 2.76$ & $101.08 \pm 1.98$ & $97.94 \pm 2.47$ & $100.30 \pm 2.82$ & $96.59 \pm 3.31$ \\
\hline 45 & $97.39 \pm 2.91$ & $96.79 \pm 3.08$ & $99.42 \pm 2.57$ & $95.28 \pm 2.34$ & $96.73 \pm 3.63$ & $92.76 \pm 2.39$ \\
\hline 60 & $95.64 \pm 2.92$ & $93.86 \pm 3.72$ & $95.23 \pm 3.12$ & $92.75 \pm 3.65$ & $94.37 \pm 2.15$ & $90.72 \pm 3.42$ \\
\hline
\end{tabular}

Table 1: Dissolution data of enantiomers of Amlodipine besylate. PD: Pure Drug; PM: Physical mixture of the drug with HPBC at 1:1 molar ratio. KN: Kneading mixture of the drug with HPBC at 1:1 molar ratio. SE1, SE2 \& SE3: Inclusion complexes of the drug with HPBC prepared by solvent evaporation method at $1: 1,1: 2$ \& $1: 3$ ratio respectively; HPBC: Hydroxy Propyl $\beta$ - Cyclodextrin; SD: Standard deviation.

\begin{tabular}{|c|c|c|c|c|c|c|}
\hline \multicolumn{7}{|c|}{$\%$ Drug release $(n=3)$} \\
\hline TIME & \multicolumn{2}{|c|}{ PD (Mean $\pm S D)$} & \multicolumn{2}{|c|}{ PM (Mean士SD) } & \multicolumn{2}{|c|}{ KN (Mean $\pm S D)$} \\
\hline ( $\min )$ & $\mathbf{R}$ & $\mathbf{s}$ & $\mathbf{R}$ & S & $\mathbf{R}$ & s \\
\hline 5 & $83.43 \pm 2.16$ & $81.15 \pm 2.73$ & $85.71 \pm 2.29$ & $84.50 \pm 2.67$ & $85.26 \pm 2.91$ & $83.27 \pm 3.42$ \\
\hline 15 & $90.32 \pm 2.41$ & $92.49 \pm 3.49$ & $95.47 \pm 3.52$ & $96.88 \pm 1.91$ & $95.75 \pm 2.75$ & $93.10 \pm 3.25$ \\
\hline 30 & $97.54 \pm 3.36$ & $98.38 \pm 2.19$ & $98.91 \pm 3.61$ & $99.09 \pm 3.31$ & $99.31 \pm 2.64$ & $98.91 \pm 2.06$ \\
\hline 45 & $94.12 \pm 2.29$ & $94.13 \pm 3.29$ & $95.83 \pm 2.49$ & $96.39 \pm 2.16$ & $98.45 \pm 2.39$ & $94.20 \pm 3.26$ \\
\hline 60 & $91.18 \pm 1.89$ & $89.88 \pm 3.35$ & $90.41 \pm 2.05$ & $91.09 \pm 3.25$ & $93.98 \pm 3.34$ & $91.31 \pm 3.27$ \\
\hline TIME & \multicolumn{2}{|c|}{ SE1 (Mean士SD) } & \multicolumn{2}{|c|}{ SE2 (Mean $\pm S D)$} & \multicolumn{2}{|c|}{ SE3 (Mean $\pm S D)$} \\
\hline ( $\min )$ & $\mathbf{R}$ & $\mathbf{s}$ & $\mathbf{R}$ & S & $\mathbf{R}$ & s \\
\hline 5 & $84.13 \pm 3.41$ & $82.15 \pm 3.12$ & $86.17 \pm 2.91$ & $85.45 \pm 3.36$ & $85.78 \pm 2.90$ & $87.64 \pm 2.28$ \\
\hline 15 & $94.56 \pm 2.42$ & $92.29 \pm 3.31$ & $96.89 \pm 2.75$ & $95.28 \pm 2.36$ & $96.36 \pm 2.64$ & $94.24 \pm 3.27$ \\
\hline 30 & $98.97 \pm 2.28$ & $98.85 \pm 2.79$ & $100.12 \pm 2.36$ & $98.91 \pm 2.78$ & $100.07 \pm 2.97$ & $96.19 \pm 3.28$ \\
\hline 45 & $96.80 \pm 2.48$ & $95.37 \pm 3.17$ & $99.57 \pm 2.68$ & $94.46 \pm 2.42$ & $96.82 \pm 3.17$ & $99.64 \pm 2.58$ \\
\hline 60 & $92.47 \pm 2.26$ & $90.24 \pm 3.23$ & $95.71 \pm 3.63$ & $90.68 \pm 3.39$ & $92.85 \pm 2.74$ & $90.02 \pm 3.13$ \\
\hline
\end{tabular}

Table 2: Dissolution data of enantiomers of Amlodipine maleate. 
Citation: Somagoni J, Reddy S, Katakam VK, Koorelli S, Manda S, et al. (2011) Preparation of Inclusion Complexes of Amlodipine Base and its Besylate and Maleate Salts with Hydroxy Propyl B -cyclodextrin -A study on Stereospecific Dissolution. Pharm Anal Acta 2:123. doi:10.4172/2153-2435.1000123

Page 6 of 8

molar concentration dependent increment in the dissolution with both the enantiomers of amlodipine base when inclusion complexes were formed by solvent evaporation technique.

The dissolution of $S$-amlodipine base was more when compared to the dissolution of $R$-amlodipine base, when inclusion complexes were not prepared. Surprisingly, when inclusion complexes were prepared

\begin{tabular}{|c|c|c|}
\hline \multirow{2}{*}{ METHOD } & \multicolumn{2}{|c|}{ P VALUE } \\
\cline { 2 - 3 } & $\mathrm{S}$ & $\mathrm{R}$ \\
\hline PM & 0.776 & 0.895 \\
\hline KN & 0.020 & 0.030 \\
\hline SE2 & 0.021 & 0.026 \\
\hline SE3 & 0.002 & 0.003 \\
\hline
\end{tabular}

Table 3(a): Racemic amlodipine base.

\begin{tabular}{|c|c|}
\hline METHOD & P VALUE \\
\hline PD & 0.679 \\
\hline PM & 0.718 \\
\hline KN & 0.012 \\
\hline SE1 & 0.004 \\
\hline SE2 & 0.032 \\
\hline SE3 & 0.020 \\
\hline
\end{tabular}

Table 3(b): Racemic amlodipine base.

Table 3: $p$ values obtained for $S \& R$ enantiomers when the dissolution values of inclusion complexes of racemic amlodipine base prepared by different methods compared with the dissolution values of pure racemic amlodipine base \{Table $3(a)\}$ and with each other $\{$ Table $3(b)\}$.

\begin{tabular}{|c|c|c|}
\hline \multirow{2}{*}{ METHOD } & \multicolumn{2}{|c|}{ P VALUE } \\
\cline { 2 - 3 } & $\mathrm{S}$ & $\mathrm{R}$ \\
\hline PM & 0.903 & 0.712 \\
\hline KN & 0.837 & 0.853 \\
\hline SE1 & 1 & 0.966 \\
\hline SE2 & 0.94 & 0.582 \\
\hline SE3 & 0.836 & 0.769 \\
\hline
\end{tabular}

\begin{tabular}{|c|c|}
\hline \multicolumn{1}{|c|}{ Table 4(a): Racemic amlodipine besylate. } \\
\hline METHOD \\
\hline PD & 0.905 \\
\hline PM & 0.728 \\
\hline KN & 0.876 \\
\hline SE1 & 0.548 \\
\hline SE2 & 0.584 \\
\hline SE3 & 0.547 \\
\hline
\end{tabular}

Table 4(b): Racemic amlodipine besylate.

Table 4: $p$ values obtained for $S \& R$ enantiomers when the dissolution values of inclusion complexes of racemic amlodipine besylate prepared by different methods compared with the dissolution values of pure racemic amlodipine besylate $\{$ Table $4(a)\}$ and with each other $\{$ Table $4(b)\}$.

\begin{tabular}{|c|c|c|}
\hline \multirow{2}{*}{ METHOD } & \multicolumn{2}{|c|}{ P VALUE } \\
\cline { 2 - 3 } & $\mathrm{S}$ & $\mathrm{R}$ \\
\hline PM & 0.557 & 0.572 \\
\hline KN & 0.81 & 0.374 \\
\hline SE1 & 0.89 & 0.567 \\
\hline SE2 & 0.646 & 0.239 \\
\hline SE3 & 0.532 & 0.392 \\
\hline
\end{tabular}

Table 5 (a): Racemic amlodipine maleate.

\begin{tabular}{|c|c|}
\hline METHOD & P VALUE \\
\hline PD & 0.905 \\
\hline PM & 0.728 \\
\hline KN & 0.876 \\
\hline SE1 & 0.548 \\
\hline SE2 & 0.584 \\
\hline SE3 & 0.547 \\
\hline
\end{tabular}

Table 5 (b): Racemic amlodipine maleate.

Table 5: $p$ values obtained for $S \& R$ enantiomers when the dissolution values of inclusion complexes of racemic amlodipine maleate prepared by different methods compared with the dissolution values of pure racemic amlodipine maleate $\{$ Table $\mathbf{5 ( a )}\}$ and with each other $\{$ Table 5(b) $\}$.

with HPBC, it was noted that the improvement in the dissolution for $R$ - amlodipine base was significantly higher than the $S$ - amlodipine base $(p<0.05)$. This stereospecific discrimination in the dissolution was clearly evident from $S / R$ ratios of amlodipine base enantiomers (Figure 7) Dissolution profiles showing $S / R$ ratio one or close to one are said to be releasing the $S$-enantiomer (Active form) and $R$-enantiomer (Inactive form) at equal rates where as dissolution profiles showing $\mathrm{S} / \mathrm{R}$ ratio more than one are said to be releasing the $S$-enantiomer faster than the $R$-enantiomer.

This peculiar result might be due to the spatial arrangement of groups on $R$-enantiomer which was more comfortable for the inclusion into the cavity of HPBC or spatial arrangement of groups on HPBC may be more effective in forming the inclusion complexes of $R$ enantiomer than $S$-enantiomer. This result was observed only with $1: 1$ and 1:2 molar ratio complexes $(\mathrm{p}<0.05)$. No stereospecificity in the dissolution of $S$ and $R$ enantiomers was observed with 1:3 inclusion complexes $\{(p>0.05$; Table $3(b)\}$. This may be due to the sufficient availability of $\mathrm{HPBC}$ to the amlodipine enantiomers when the inclusion complexes were made with 1:3 molar ratio, hence no competition for the HPBC molecules as a result there was no stereospecificity between amlodipine enantiomers.

Loss of stereoselective discrimination in the dissolution of besylate and maleate salts was may be due to the similarity in the way how the besylate and maleate enantiomers interact and form the hydrogen bonds with water molecules or the steric hindrance which is because of the presence of larger besylate and maleate groups in the case of amlodipine besylate and maleate salts.

\section{Statistical analysis}

From the statistical analysis of entire data it was found that after complexation with HPBC a significant improvement in the dissolution $\&$ stereospecific drug dissolution was found in the case of amlodipine base but not besylate and maleate salts. 


\section{Dissolution profiles of Amlodipine base and its inclusion complexes}

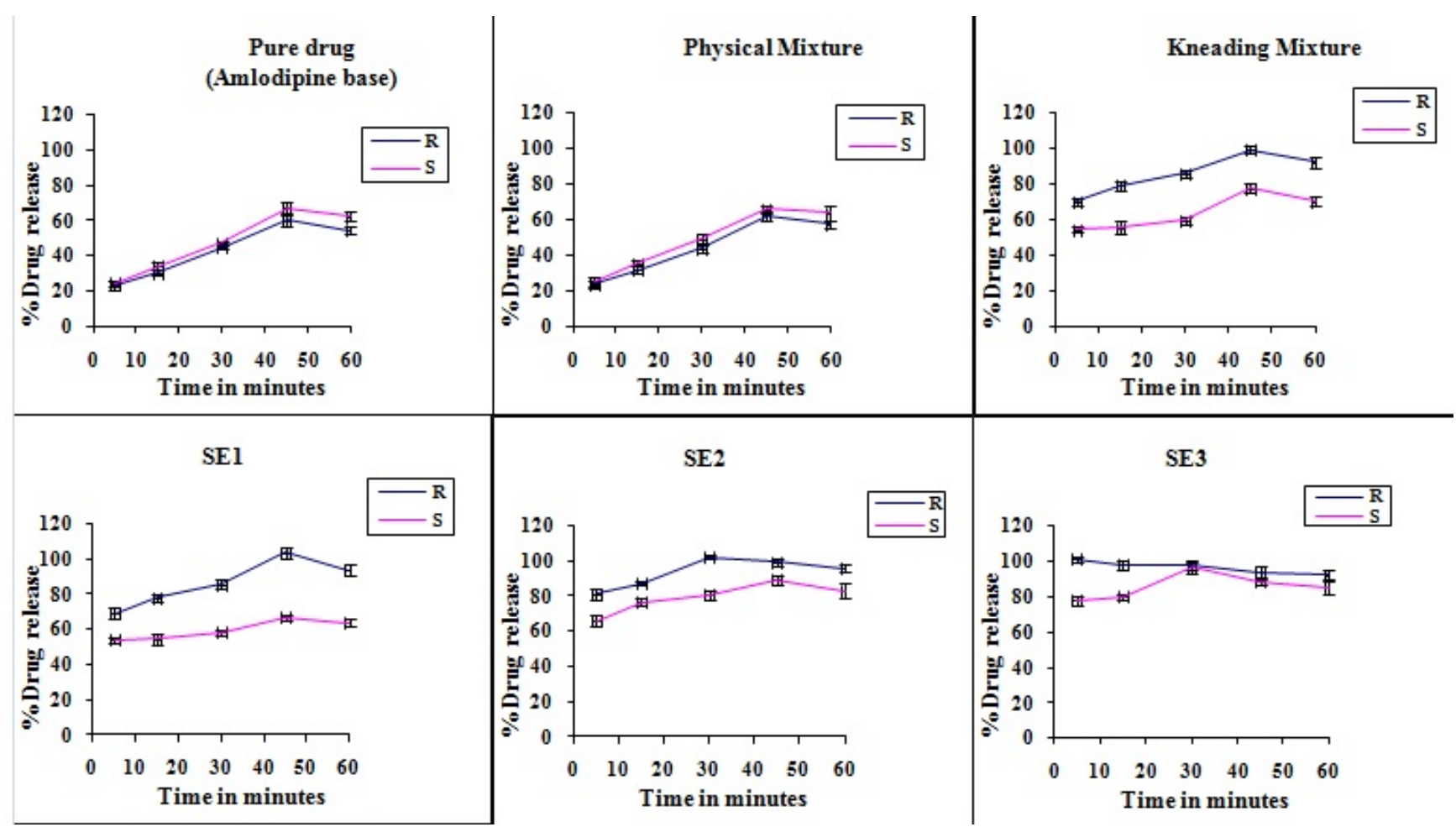

Figure 6: Cumulative \% drug release profiles of amlodipine base and its inclusion complexes with HPBC prepared by physical mixing, kneading \& solvent evaporation methods.

$\mathrm{S} / \mathrm{R}$ ratios of Amlodipine base and its inclusion complexes

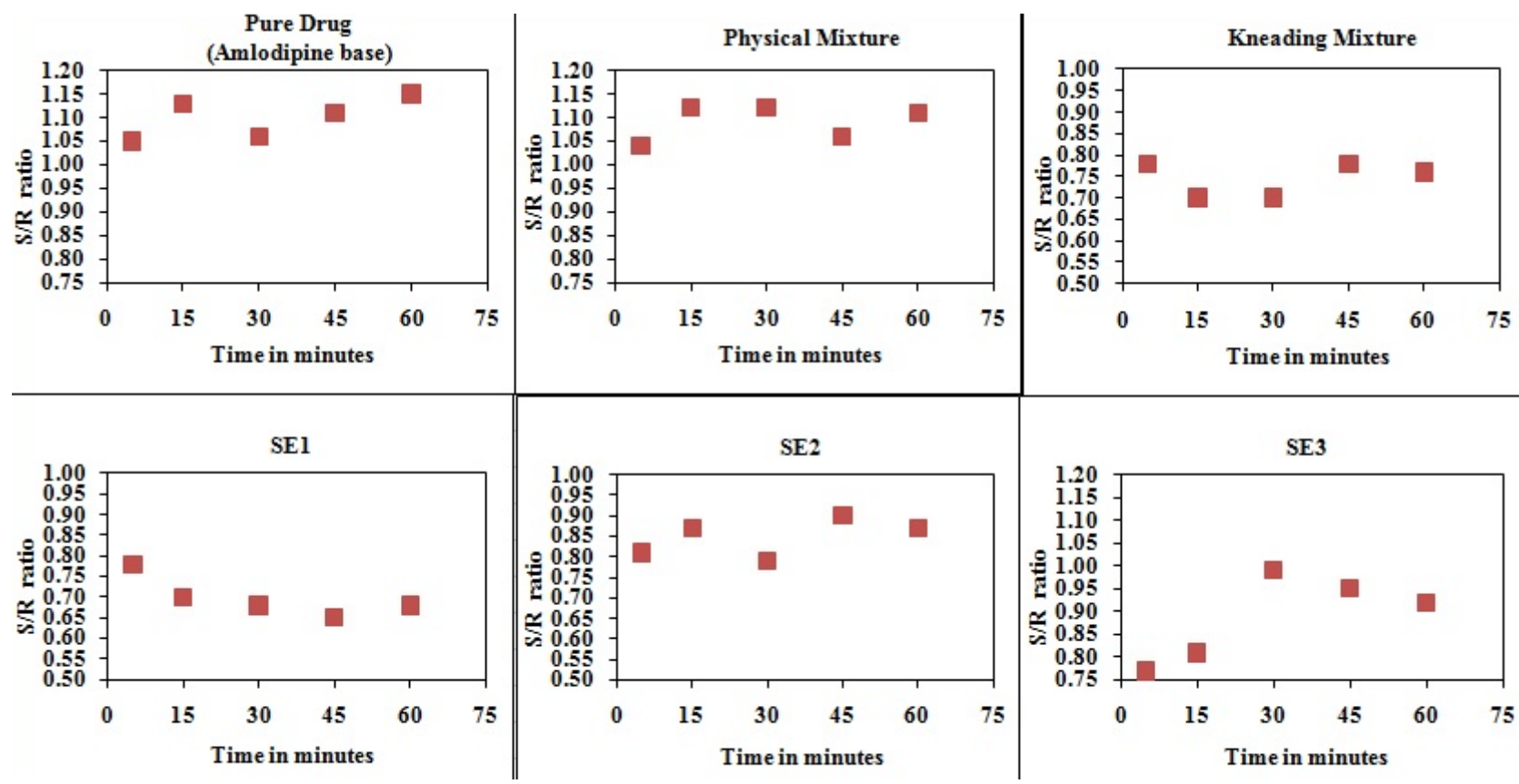

Figure 7: S/R ratios of amlodipine base and its inclusion complexes with HPBC prepared by physical mixing, kneading \& solvent evaporation methods. 
Citation: Somagoni J, Reddy S, Katakam VK, Koorelli S, Manda S, et al. (2011) Preparation of Inclusion Complexes of Amlodipine Base and its Besylate and Maleate Salts with Hydroxy Propyl B -cyclodextrin -A study on Stereospecific Dissolution. Pharm Anal Acta 2:123. doi:10.4172/2153-2435.1000123

Page 8 of 8

\section{Conclusions}

Inclusion complexes of amlodipine base and its besylate and maleate salts with hydroxy propyl $ß$-cyclodextrin were prepared but the true inclusion was done only in the case of amlodipine base and hence improvement in the dissolution was found only with amlodipine base. In case of physical mixing no inclusion complexes were formed even with amlodipine base. Significant stereospecific dissolution was observed with amlodipine base when its inclusion complexes were prepared with 1:1 \& 1:2 molar ratios but not with 1:3 molar ratio. The DSC and FTIR studies were used to characterize the inclusion complexes and to support the stereospecific dissolution of amlodipine base enantiomers.

\section{Acknowledgements}

The authors are very thankful to Smruthi Organic Industries, Maharashtra \& Nectar Pharma Pvt. Ltd., India for providing the Amlodipine enantiomers and Hydroxypropyl $ß$-cyclodextrin (HPBC). One of the authors (S. JaganMohan) is especially thankful to AICTE, New Delhi for providing the National Doctoral Fellowship.

\section{References}

1. Lee P, Han J, Song T, Sung J, Kwon O, et al. (2007) Physicochemica characterization and bioavailability of a novel intestinal metabolite of ginseng saponin complexes with $\beta$-cyclodextrin. Int J Pharm 316: 29-36.

2. Shen $Y$, Ying W, Yang S, Wu L (2006) Determination of the inclusion complex between gossypol and $\beta$-cyclodextrin. Spectrochim. Acta Part A 65: 169-172.

3. Lahiani-Skiba M, Barbot C, Bounoure F, Joudieh S, Skiba M (2006) Solubility and dissolution rate of progesterone-cyclodextrin-polymer systems. Drug Dev Ind Pharm 32: 1043-1058.

4. Figueiras A, Sarraguça JM, Carvalho RA, Pais AA, Veiga FJ (2007) Interaction of omeprazole with a methylated derivative of $\beta$-cyclodextrin: phase solubility, NMR spectroscopy and molecular simulations. Pharm Res 24: 377-389.
5. Pfammatter JP Clericetti-Affolter C, Truttmann AC, Busch K, Laux-End R, et al. (1998) Amlodipine once daily in systemic hypertension. Eur J Pediatr 157 618-621.

6. Flynn JT, Smoyer WE, Bunchman TE (2000) Treatment of hypertensive children with amlodipine. Am J Hypertens 13: 1061-1066.

7. Meredith PA, Elliott HL (1992) Clinical pharmacokinetics of amlodipine. Clin Pharmacokinet 22: 22-31.

8. Lorfen H, Litold M (1994) Enontio slictior disposition of oral amlodipine in healthy volunteers. Chirality 6: 531-6.

9. Hirmoth MS, Dighe G (2002) A randomized, double-blind, double dummy multicentric, horollel group. Comparative clinical trial of S-amlodipine $2.5 \mathrm{mg}$ were amlodipine $5 \mathrm{mg}$ in the treatment of mild to moderate hypertension. JAMA India 1: 86-92.

10. Lekha P, Hiremath MS, Kerkar PG, Manade VG (2004) Multi centric clinica trial of S-amlodipine $2.5 \mathrm{mg}$ versus amlodipine $5 \mathrm{mg}$ in the treatment of mild to moderate hypertension - A randomised double blind clinical trial. JAPI 52 197-202.

11. Zhang XP, Loke KE, Mital S, Chohwala S, Hintze TH (2002) Paradoxica release of nitric oxide by an L-left calcium channel antagonist, the $\mathrm{R}+$ in antiomir of amlodipine. J Cardiovas Pharmacol 39: 208-14.

12. Caldwell $J$ (1992) The importance of stereochemistry in drug action and disposition. J Clin Pharmacol 32: 925-9.

13. Landoni MF, Soraci A (2001) Pharmacology of chiral compounds: 2-Arylpropionic acid derivatives. Current Drug Metabolism 2: 37-51.

14. Eichelbaum M, Gross AS (1996) Stereochemical aspects of drug action and disposition. Advances in Drug Research 28: 1-64.

15. Maggi L, Massolini G, De Lorenzi E, Conte U, Caccialanza G (1996) Evaluation of stereoselective dissolution of verapamil hydrochloride from matrix tablets press-coated with chiral excipients. Int J Pharm 136: 43-51. 